\title{
Exploring unbalanced urban spatial expansion in sprawling cities. Case study of Kimara Matangini, Kibululu and Dovya settlements in Dar es Salaam City, Tanzania
}

\author{
John Modestus Lupala \\ School of Spatial Planning and Social Sciences, Ardhi University, \\ P.O.Box 35176, Dar es Salaam, Tanzania; lupalajohn@yahoo.com \\ Received: 11 September 2021; Revised: 6 November 2021; Accepted: 24 November 2021; \\ Published online: 29 November 2021
}

\begin{abstract}
Unbalanced urban expansion characterize urban growth in rapidly urbanizing cities in the global south. This pattern of growth has resulted into difficulties in provision of services which leads to challenges of livability within settlements. Services such as education, health, water supply and road network are not easily accessible because of unbalanced growth. Balanced urban growth is concerned with three key themes: place, people and planning. The aim of this study is to help policy makers, local governments, developers, planners and service providers to analyze and visualize different options and scenarios to achieve balanced urban expansion. The overall goal of balanced urban spatial expansion is to achieve livable, sustainable, resilient and affordable cities. This paper adopted both qualitative and quantitative approaches of data collection and subsequent analysis and captured empirical evidence from primary and secondary data sources. The key methods included; literature review, interviews and observations. The research was conducted in three settlements with a sub-ward status namely; Kimara Matangini, Kibululu and Dovya. Findings indicate that the drivers of urban spatial growth are related to economic and social factors, people's choice and satisfaction of residential areas, modalities in land acquisition, provision or non-provision of services, mobility, proximity to services and proximity to the city centre. Yet the emerging development pattern pose some challenges to residents settling in these areas because of unavailability or longer distances to basic services. This pattern of growth has culminated into unbalanced urban growth. This study recommends that the government in collaboration with key stakeholders should strengthen development control even in unplanned settlements so as to monitor development and potential service requirements, acquire parcels of land for future service provision, strengthen regularization activities to provide for land reserves for infrastructure and conduct a city wide analysis on the unbalance pattern, especially in rapidly urbanizing peri-urban areas.
\end{abstract}

Key words: unbalanced spatial growth, service availability, accessibility, livability, density

Citation: Lupala, J.M. (2021). Exploring unbalanced urban spatial expansion in sprawling cities. Case study of Kimara Matangini, Kibululu and Dovya settlements in Dar es Salaam City, Tanzania. Central European Journal of Geography and Sustainable Development, 3(2), 62-84. https://doi.org/10.47246/CEJGSD.2021.3.2.5

https://doi.org/10.47246/CEJGSD.2021.3.2.5

| Full text | 